\title{
Overexpression of wild-type p53 gene renders MCF-7 breast cancer cells more sensitive to the antiproliferative effect of progesterone
}

\author{
M Alkhalaf and A M El-Mowafy ${ }^{1}$ \\ Department of Biochemistry, Faculty of Medicine, Kuwait University, Kuwait, PO Box 24923, Safat 13110, Kuwait \\ ${ }^{1}$ Department of Applied Therapeutics, Faculty of Pharmacy, Health Sciences Center, Kuwait University, Kuwait, PO Box 24923, Safat 13110, Kuwait \\ (Requests for offprints should be addressed to M Alkhalaf; Email: m_alkhalaf@hsc.kuniv.edu.kw)
}

\begin{abstract}
We have recently shown that growth inhibition of breast cancer cells by progesterone is due to the induction of cell differentiation, but not apoptosis. Because the tumor suppressor protein p53 plays a central role in normal cell growth and in tumor suppression, we have examined the effect of progesterone on the levels of this protein in MCF-7 cells. We show here that the antiproliferative effect of progesterone is accompanied with downregulation of endogenous p53 protein. To study the effect of progesterone on cell growth in the presence of normal levels of p53 protein, we used transient transfection to overexpress p53 protein. MCF-7 cells were transfected
\end{abstract}

with a p53 expressing vector that contains p53 human cDNA under the control of a cytomegalovirus promoter. Cell growth, cell viability, and apoptosis were analyzed in the transfected cells after six days of exposure to $100 \mathrm{nM}$ progesterone. We show here that progesterone significantly enhances growth inhibition and apoptosis in MCF-7 cells overexpressing p53, but not in cells transfected with the control vector. These data suggest that re-establishing p53 function in MCF-7 breast cancer cells renders them more sensitive to the growth inhibitory effect of progesterone.

Journal of Endocrinology (2003) 179, 55-62

\section{Introduction}

The steroid hormone progesterone is an important growth regulator of normal and malignant breast epithelial cells, and is used to treat hormone-dependent breast tumors (Clarke \& Sutherland 1990, Santen et al. 1990, Pasqualini et al. 1998, Sutherland et al. 1998). However, the exact molecular mechanism of the antiproliferative effect of progesterone is poorly understood and apart from the requirement of its receptor (Horwitz 1993, Osborne 1998), little is known about the mechanism by which it mediates growth inhibitory effects on hormone responsive cells. Several studies have shown that growth inhibition of breast cancer cell lines by progesterone is associated with altered expression of genes that have a role in growth arrest and differentiation (Alkhalaf \& Murphy 1992, Musgrove et al. 1996, Kester et al. 1997, Swarbrick et al. 2000). The p53 tumor suppressor protein, which is a transcription factor capable of inducing either growth arrest or apoptosis (Lane 1994, Levine 1997), is frequently inactivated by mutation or other mechanisms in human breast cancer (Olivier \& Hainaut 2001). There are conflicting reports about the regulation of the p53 protein level by progesterone in breast cancer cells. For instance, Moudgil et al. (2001) reported that the treatment of T47D breast cancer cells with the synthetic progestin, R5020, lowered the p53 levels to $30 \%$ of the control level. On the other hand, Formby \& Wiley (1998) showed that the antiproliferative effect of progesterone was due to the induction of apoptosis and that p53 mRNA levels were upregulated as detected by semi-quantitative RT-PCR analysis. The T47D human breast cancer cells used by both authors contained a mutated p53 gene (Schafer et al. 2000). Moore et al. (2000) suggested that the effects of progesterone on p53 and on other apoptotic proteins might contribute to the survival of breast cancer cells and to the development of resistance to progestin therapy. In this report we used the MCF-7 human breast cancer cell line which harbors a wild-type p53 gene. By using these cells, we have previously shown that growth inhibition of breast cancer cells by progesterone is due to the induction of cell differentiation and not to apoptosis (Alkhalaf et al. 2002). Our data show that progesterone inhibits the growth of MCF-7 cells and this growth inhibition is associated with down-regulation of p53 levels. We report here that progesterone may protect breast cancer cells from apoptosis by altering p53 protein levels. We present evidence that re-establishing p53 expression in these cells enhances the growth inhibitory effect of progesterone by activating apoptosis. 


\section{Materials and Methods}

The MCF-7, T47D and ZR75-1 breast cancer cell lines were kindly provided by Bohdan Wasylyk (IGBMC Core Facility, Strasbourg, France). All three cell lines are classified as progesterone receptor positive and estrogen receptor positive. The MCF-7 cells contain functional p53 protein localized at the nucleus, whereas T47D cells have a mutated type of $\mathrm{p} 53$ which is localized at the cytoplasm (Schafer et al. 2000). ZR75-1 contains normal levels of p53, but it is not known whether the protein is functional or not.

The cells were grown in RPMI 1640 medium (Gibco BRL) supplemented with 5\% fetal bovine serum (FBS), glutamine and gentamicin. Cells were plated at $5 \times 10^{5}$ cells $/ 35 \mathrm{~mm}$ diameter multi-wells (for cell proliferation, apoptosis and morphology analysis) or at $3 \times 10^{6}$ cells/ $25 \mathrm{~cm}^{-2}$ (for Western blotting assay) and maintained in a $5 \% \mathrm{CO}_{2}$ humidified atmosphere at $37^{\circ} \mathrm{C}$ for $48 \mathrm{~h}$.

\section{Western blot analysis}

Cells were washed twice with PBS buffer and then the preheated $\left(95^{\circ} \mathrm{C}\right)$ lysis buffer $(20 \mathrm{mM}$ Tris- $\mathrm{HCl} \mathrm{pH} 7 \cdot 4$, $20 \mathrm{mM}$ dithiothreitol (DTT), $2 \mathrm{mM}$ EDTA (sodium salt), 1\% Triton X-100, 1\% NP40, 1\% sodium deoxycholate, $1 \mathrm{mM}$ sodium pyrophosphate, $1 \mathrm{mM}$ sodium orthovandate (prepared in Tris buffer) and $1 \mathrm{mM}$ phenylmethylsulfonylfluoride) was added directly to the cell monolayer. The cells were scraped and mixed with a rubber policeman, transferred to Eppendorf tubes and centrifuged at $13000 \mathrm{~g}$ for $5 \mathrm{~min}$. The resulting supernatant was saved and the protein was determined by the Bradford method. Extracts were boiled for $3 \mathrm{~min}$ in $2 \times$ SDS buffer. Equal amounts of protein were loaded on $10 \%$ SDS-PAGE according to the method of Laemmli, then electrotransferred to nitrocellulose membranes. The blots were incubated with p53 (DO1) monoclonal antibodies (Oncogene Research, Cambridge, MA, USA) at a 1/500 dilution for $1 \mathrm{~h}$, then incubated with peroxidase-conjugated anti-mouse $\operatorname{IgG}$ (Jackson Laboratory, West Grove, PA, USA) at a 1/2000 dilution. Immunoreactive bands were visualized by incubation with luminol (according to the manufacturer's instructions; ECL Western blotting detection system from Amersham). TATA-binding protein (TBP) monoclonal antibody was used as a loading control (kindly provided by IGBMC Core Facility, Illkirch, France).

\section{Transient transfection of MCF-7 with p53 cDNA expression vector}

MCF-7 cells were maintained in RPMI 1640 medium + $10 \%$ FBS + antibiotics at $37^{\circ} \mathrm{C}$ with $5 \% \mathrm{CO}_{2}$. They were transfected either with $3 \mu \mathrm{g}$ cytomegalovirus (CMV) expression vector (pcDNA3, obtained from Invitrogen), in $36 \mathrm{~mm}$ plates (6-well cluster, Nunc, Naperville, IL, USA) or with $3 \mu \mathrm{g}$ CMV vector containing human p53 cDNA (kindly provided by the IGBMC Core Facility, Illkirch, France) by using lipofectamine (Gibco-BRL). Twentyfour hours later the cells were fixed with methanol and analyzed by immunocytochemistry with antibodies against p53 followed by FITC-conjugated goat anti-mouse and propidium iodide to detect nuclei. The cells were visualized with a fluorescence microscope equipped with dual filters and photographed. To study the effect of progesterone on MCF-7 cells that overexpress p53, the p53transfected as well as the control cells (transfected with the empty vector) were treated with vehicle alone or increasing concentrations of progesterone $(1,10,100,1000$ and $5000 \mathrm{nM}$ ). The medium with or without progesterone was changed every second day. The cells were left for 6 days then harvested and cell numbers were counted on a Coulter counter. In each experiment, triplicate dishes were used for each data point.

\section{4,6-Diamidino-2-phenylindol (DAPI) and Trypan Blue staining for the detection and quantification of apoptosis}

The cells $\left(5 \times 10^{4}\right)$ were seeded into $35 \mathrm{~mm}$ diameter multi-wells containing 5\% FBS for $48 \mathrm{~h}$. The cells were then treated with vehicle (control) or with $100 \mathrm{nM}$ progesterone in the presence of 5\% FBS. Before the processing of cells for DAPI staining, the cell morphology was examined and photomicrographs were taken for each treatment by using phase contrast microscopy. To identify cells undergoing apoptosis we used the DAPI staining method. Cells were washed with PBS, fixed with 100\% methanol and then stained with DAPI $(1 \mu \mathrm{g} / \mathrm{ml})$. The stained nuclei were visualized under a Zeiss Axioplan microscope equipped with a DAPI filter using a $40 \times$ oil objective. Photographs were taken with Kodak TMax 400 film. Condensed or fragmented nuclei were scored as apoptotic cells. To quantify apoptosis, three random fields were counted, with each field consisting of $\sim 100$ cells.

In another set of experiments, the rate of cell death with each type of treatment was estimated by the Trypan Blue exclusion assay. After three days of treatment with progesterone, the medium containing floating cells was collected and the adhering cells were detached by trypsinization and pooled with the floating ones. Cell viability was estimated after adding an equivalent volume of a $0 \cdot 125 \%$ Trypan Blue solution to an aliquot of the whole suspended cells followed by counting, under the microscope, the proportion of unstained versus total cells deposited in a hemacytometer. At least five counts over different fields of about 100 cells were made to evaluate the average cell viability in each group of treated cells. The viability in control cells was considered to be $100 \%$.

\section{Statistical analysis}

Data were analyzed by Student's $t$-test, and $P<0.05$ was considered significant. 


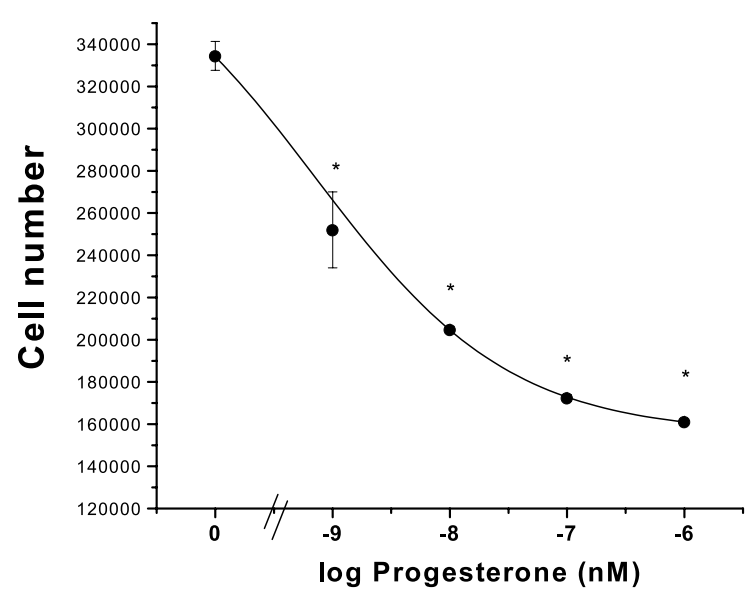

Figure 1 Dose-dependent effect of progesterone on the proliferation of MCF-7 cells. Cells were incubated with increasing concentrations of progesterone in 5\% serum for 4 days. Results are presented as means \pm S.D. from two experiments using triplicate sets of dishes. ${ }^{*} P<0 \cdot 05$, treated samples were significantly different from the control.

\section{Results}

Effect of progesterone on cell growth of non-transfected MCF-7 cells

For the dose-response experiment, MCF-7 cells were incubated with vehicle (ethanol) or with increasing concentrations of progesterone $(0,1,10,100,1000 \mathrm{nM})$ in the presence of $5 \%$ FBS for 4 days. Cell growth was determined by counting the cell number in triplicate sets of dishes. At all concentrations, progesterone caused significant growth inhibition $(P<0 \cdot 05)$ (Fig. 1). For the timecourse experiment, MCF-7 cells were incubated with $100 \mathrm{nM}$ progesterone or with vehicle in the presence of $5 \%$ FBS and cell number was determined after 1, 2, 3 or 4 days of treatment. Note the decrease in cell number with increasing length of progesterone treatment. The cell number in progesterone-treated $\mathrm{MCF}-7$ cells corresponded to approximately $50 \%$ of the control after 4 days of treatment (Fig. 2).

Growth inhibition by progesterone is associated with p53 down-regulation

The MCF-7 cell line, which contains the wild-type p53 gene, was used to study the regulation of $\mathrm{p} 53$ by progesterone. Our aim was to evaluate the involvement of p53 in progesterone induction of growth inhibition. We used Western blotting analysis with p53 antibody to assess the level of p53 protein in MCF-7 cells treated with progesterone for $0,2,4,6,12,24$ and $30 \mathrm{~h}$. Figure 3 shows that $100 \mathrm{nM}$ progesterone caused down-regulation of the endogenous p53 protein. The decrease in p53 levels starts as early as $12 \mathrm{~h}$ after treatment and maximal inhibition was

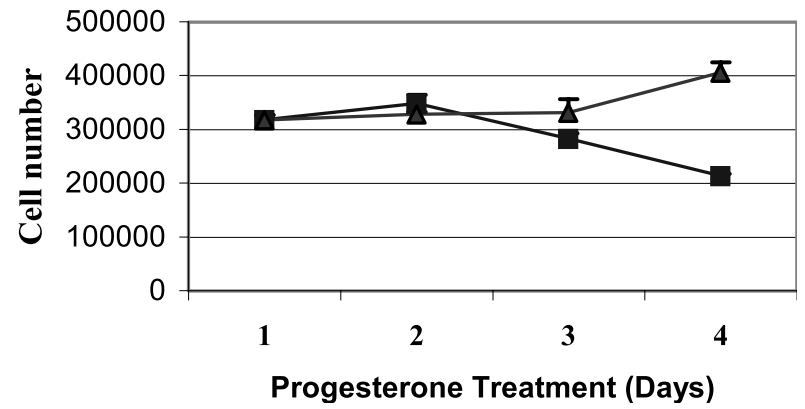

Figure 2 Time-course effect of progesterone on the proliferation of MCF-7 cells. MCF-7 cells were incubated with $100 \mathrm{nM}$ progesterone $(\boldsymbol{\square})$ or with vehicle $(\boldsymbol{\Delta})$ in the presence of $5 \%$ FBS. Cell number was determined after 1, 2, 3 or 4 days of treatment. The control MCF-7 cells are growing over after 4 days in the presence of $5 \%$ FBS. Note the decrease in cell number with increasing length of progesterone treatment $(50 \%$ as of control in day 4).

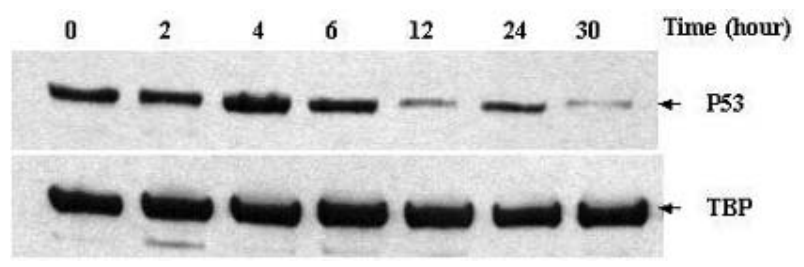

Figure 3 Time-course effect of progesterone on p53 protein levels in MCF-7 cells. Cells were treated with $100 \mathrm{nM}$ progesterone and harvested after different periods of time. Twenty micrograms of extract were subjected to Western blotting analysis to determine the relative amounts of $\mathrm{p} 53$ and TBP (used as a loading control) proteins.

observed after $30 \mathrm{~h}$ of treatment. To show that downregulation of $\mathrm{p} 53$ is specific to progesterone treatment, the same blotting membrane was re-probed with the TBP antibody. Figure 3 shows that TBP was not altered by progesterone treatment in MCF-7 cells. Therefore this antibody was used as a loading control. This inhibitory effect on p53 expression in MCF-7 cells was specific for progesterone treatment (Fig. 4, lane 6) and was not observed with the use of another type of growth inhibitory drug, the antiestrogen 4-hydroxytamoxifen (Fig. 4, lane 7) or with the growth stimulating estrogen, estradiol-17 $\beta$ (Fig. 4, lane 8). The inhibitory effect of progesterone in MCF-7 cells was not detected in another breast cancer cell line, ZR75-1 (Fig. 4, lane 2). In the same culture conditions, progesterone inhibited the growth of another breast cancer cell line, T47D, in a dose- and timedependent fashion (data not shown). T47D cells contain a mutated form of $\mathrm{p} 53$ protein and treatment with progesterone has no effect on p53 levels (data not shown). These results show that growth inhibition induced by progesterone is independent of p53 regulation, at least in the T47D and ZR75-1 cell lines. 


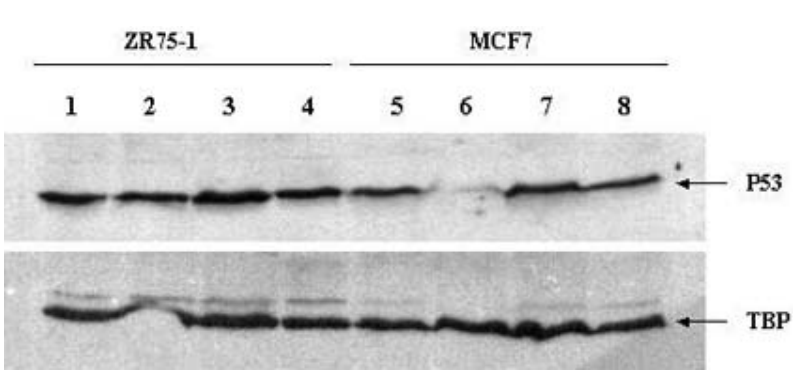

Figure 4 Effect of medroxyprogesterone acetate (MPA), 4-hydroxytamoxifen (OH-TAM) and estradiol on p53 protein levels in breast cancer cell lines. The results of Western blotting analysis of cells treated for $24 \mathrm{~h}$ with vehicle (lanes 1, 5), $100 \mathrm{nM}$ MPA (lanes 2, 6), $100 \mathrm{nM} \mathrm{OH-TAM}$ (lanes 3, 7), or $100 \mathrm{mM}$ estradiol (lanes 4, 8) are shown. Immunoblotting was performed with monoclonal antibodies specific for p53 and TBP (loading control).

\section{p53 overexpression enhances the progesterone effect on cell} growth and apoptosis

The observation that endogenous p53 protein levels were down-regulated by progesterone in MCF-7 cells prompted us to check the consequences of re-establishing the p53 expression in the cells by exogenous expression using transient transfection experiments. In the beginning, we examined the efficiency of transfection of MCF-7 cells with the CMV expression vector. Cells transfected with $3 \mu \mathrm{g}$ p53 expression vector showed high levels of nuclei with p53 protein (Fig. 5, lower panel), as compared with cells transfected with the empty vector (Fig. 5, upper panel) which showed few positive nuclei representing endogenous $\mathrm{p} 53$. The total number of cells expressing p53 was scored in both CMV and CMV-p53 transfected cultures. The percentage of cells with nuclear staining in CMV and CMV-p53 transfected cells was 5\% and 11\% respectively. We used Western blot analysis to estimate the amount of p53 levels achieved by transient transfection. MCF-7 cells were transfected with expression vector ( $3 \mu \mathrm{g} / \mathrm{well})$ for CMV vector and CMV vector containing human p53 cDNA. The cells were treated with vehicle or with $100 \mathrm{nM}$ progesterone for $24 \mathrm{~h}$. p53 levels were more than twofold higher in MCF-7 cells transfected with CMV-p53 vector than in CMV transfected cells as revealed by densitometry (Fig. 6).

To study the effect of exogenous p 53 on progesteroneinduced growth inhibition, the transfected cells were treated with vehicle alone or increasing concentrations of progesterone (1, 10, 100, 1000 and $5000 \mathrm{nM})$. Figure 7 shows that MCF-7 cells overexpressing p53 are more sensitive to progesterone-induced growth inhibition. Cell number in CMV-p53 transfected cells was reduced to $71 \cdot 6,70 \cdot 5$ and $65 \%$ in cells treated with $0 \cdot 1,1$ or $5 \mu \mathrm{M}$ progesterone respectively, as compared with cells transfected with the empty vector $(P<0 \cdot 05)$. This significant sensitivity to progesterone in cells overexpressing exogenous p53 was due to decreasing cell viability, tested by using the Trypan Blue exclusion test. Figure 8 shows a decrease in cell viability in CMV-p53 transfected cells in response to progesterone compared with cells transfected with the CMV empty vector. Cell viability in CMV-p53 transfected cells was reduced to $78 \cdot 6,61 \cdot 9$ and $44 \cdot 8 \%$ in cells treated with $0 \cdot 1,1$ or $5 \mu \mathrm{M}$ progesterone respectively, as compared with cells transfected with the CMV vector $(P<0 \cdot 05)$. To further ascertain the cell viability findings in the transfected cells, we examined the effect of progesterone on DNA fragmentation by using the DAPI staining method. Figure 9A shows a representative staining pattern observed in MCF-7 cells transfected with CMV vector. DAPI staining did not reveal any nuclear changes characteristic of apoptosis, whereas a marked alteration is observed with cells transfected with the CMV-p53 vector after treatment with $100 \mathrm{nM}$ progesterone (Fig. 9B). Quantification of apoptotic cells by scoring morphologically aberrant nuclei (condensed and fragmented nuclei) showed that the percentages of progesterone-induced apoptosis with control (CMV vector) and p53 overexpressing cells (CMV-p53) were $8 \cdot 5 \pm 3$ and $54 \cdot 5 \pm 5 \cdot 5$ respectively. However, the DNA ladder test performed on MCF-7 cells treated under the same conditions did not show significant DNA fragmentation which may be attributed to the high serum concentration present in the culture medium. When the cells were transfected with CMV-p53 cDNA or with CMV vector and kept in culture for six days without the addition of progesterone, CMV-p53 had no significant effect on cell growth or viability (Figs 7 and 8). In other words, the overexpression of p53 per se has no effect on cell growth or viability, implying that the progesterone machinery is crucial for the induction of apoptosis.

\section{Discussion}

Depending on the experimental model system, progesterone can elicit either proliferative or antiproliferative effects on breast epithelial growth (Lange et al. 1999, Thuneke et al. 2000). The antiproliferative effect may be due to the induction of cell differentiation (Kester et al. 1997) or to the stimulation of apoptosis (Formby \& Wiley 1999, Horita et al. 2001). We and others showed that progesterone can protect MCF-7 cells from dying by apoptosis (Ory et al. 2001, Alkhalaf et al. 2002). We showed evidence that progesterone may protect breast cancer cells from apoptosis but promotes their differentiation by activating the Akt/ PI3-kinase pathway. Moore et al. (2000) suggested that progestins in T47D cells (known to have a mutated p53 gene) serve as survival factors and also stimulate proliferation, implying a possible similar role in breast cancer patients. They showed that the effects of progestin on breast cancer cell survival were accompanied by upregulation of the antiapoptotic protein bcl-xL, consistent with a defective p53 function in these cells. We have extended 


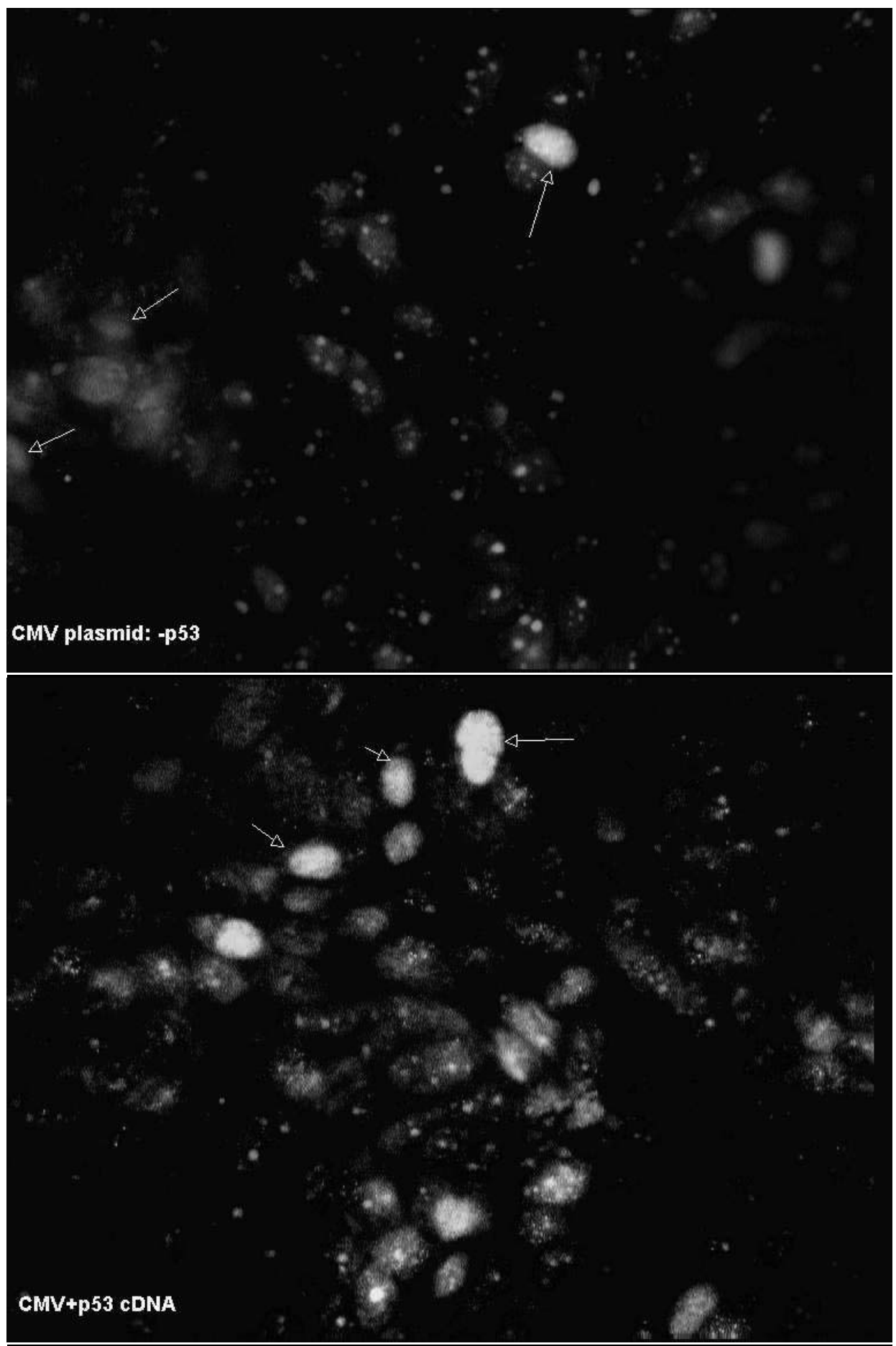

Figure 5 Transient transfection of MCF-7 human breast cancer cells with human p53 cDNA. MCF-7 cells were transfected with expression vector $(3 \mu \mathrm{g} /$ well) for CMV vector (control) (upper panel) and CMV vector containing human p53 cDNA (lower panel) by using lipofectamine (Gibco-BRL).

Twenty-four hours later the cells were fixed with methanol and analyzed by immunocytochemistry with antibodies against p53 followed by FITC-conjugated goat anti-mouse and propidium iodide to detect nuclei. The cells were visualized with a fluorescence microscope equipped with dual filters, and photographed. Arrows indicate nuclei with p53 protein. 


\section{- Pne Pne}

\section{CMV CMV-P53}

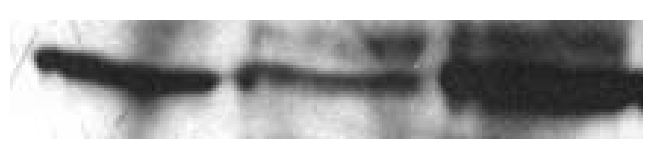

P53

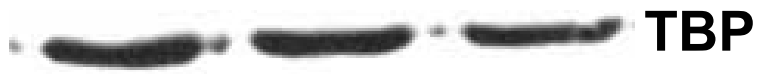

Figure 6 Western blotting of transiently transfected MCF-7 human breast cancer cells with human p53 cDNA. MCF-7 cells were transfected with expression vector ( $3 \mu \mathrm{g} /$ well) for CMV vector and CMV vector containing human p53 cDNA. The cells were treated with vehicle or with $100 \mathrm{nM}$ progesterone for $24 \mathrm{~h}$. Twenty micrograms of extract were subjected to Western blotting analysis to determine the relative amounts of p53 and TBP (used as a loading control) proteins. MCF-7 cells transfected with CMV-p53 vector contained twofold more p53 than CMV transfected cells. Pne, $100 \mathrm{~nm}$ progesterone. -, vehicle.

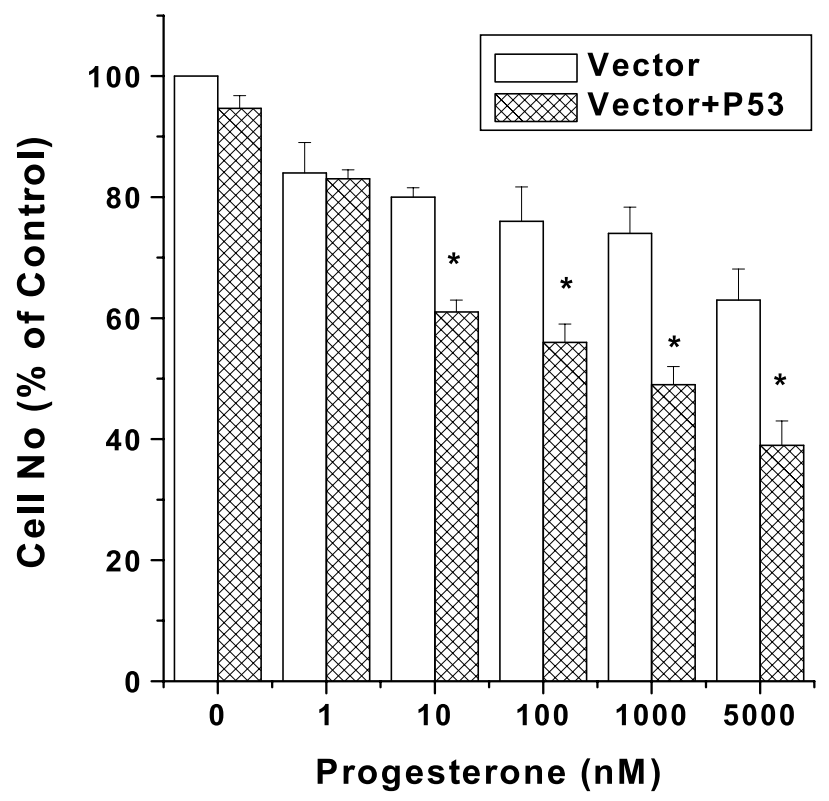

Figure 7 Effect of altered p53 expression on the growth response of MCF-7 cells to progesterone. Cells were either transiently transfected with CMV-p53 vector or with the empty CMV vector as described in Materials and Methods. The cells were then treated with vehicle alone or increasing concentrations of progesterone as indicated. The medium with or without progesterone was changed every second day. The cells were left for 6 days then harvested and cell numbers were counted on a Coulter counter. In each experiment, triplicate dishes were used for each data point. Note that MCF-7 cells transfected with p53 cDNA are more sensitive to progesterone compared with cells transfected with the control vector. ${ }^{*} P<0.05$ significantly different compared with vector alone.

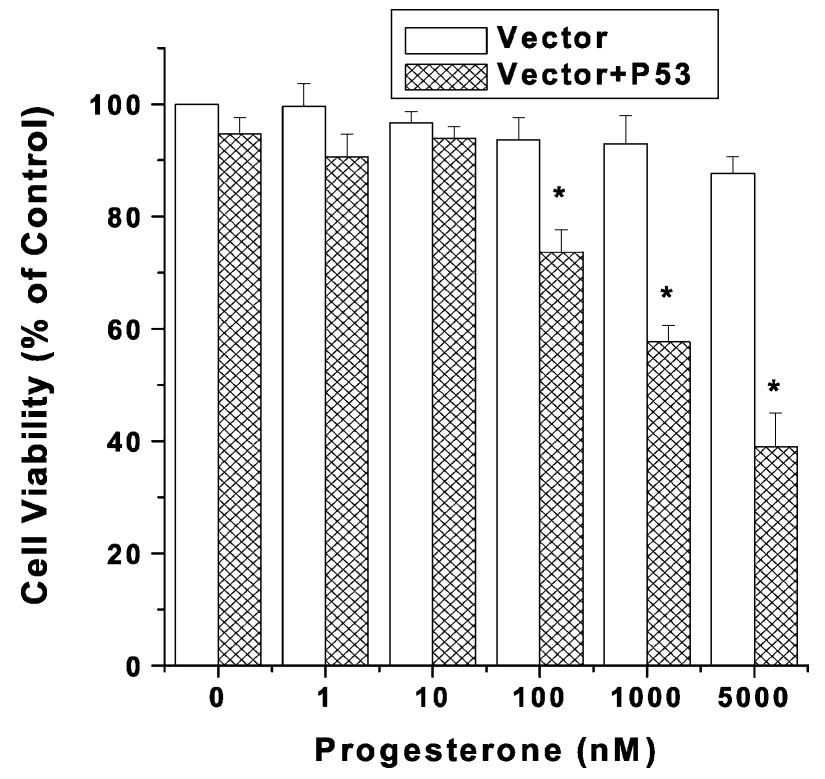

Figure 8 Effect of altered p53 expression on the cell viability of MCF-7 cells to progesterone. Cells were either transiently transfected with CMV-p53 vector or with the empty CMV vector. The cells were then treated with vehicle alone or increasing concentrations of progesterone, as indicated, for 4 days. After this incubation, the medium containing floating cells was collected and the adhering cells were detached by trypsinization and pooled with the floating ones. Cell viability was estimated after adding an equivalent volume of a $0.125 \%$ Trypan Blue solution to an aliquot of the whole suspended cells and counting under the microscope the proportion of unstained versus total cells deposited in a hemacytometer. At least five counts over different fields of about 100 cells were made to evaluate the average cell viability in each group of treated cells. The viability in control cells was considered as $100 \%$. Note the decrease in cell viability in CMV-p53 transfected cells in response to progesterone compared with cells transfected with the CMV empty vector. ${ }^{*} P<0.05$ significantly different compared with vector alone.

these observations by showing that the absence of apoptosis in MCF-7 cells treated with progesterone is associated with down-regulation of the endogenous $\mathrm{p} 53$ protein. In other words, it seems that progesterone, by stimulating the expression of antiapoptotic protein and/or by downregulating apoptotic protein, enables the cells to survive and to escape from dying by apoptosis. Whether progesterone directly regulates the transcription of the p53 gene or alternatively acts by an indirect or postranscriptional mechanism remains to be determined. However, Castoria et al. (1999) using MCF-7 cells presented evidence that progestins act on cell cycle progression by a nontranscriptional action.

Several reports showed that the accumulation of p53 mutations in human breast cancer is associated with a high proliferation rate in the tumor, an association that is expected in view of the role of $\mathrm{p} 53$ as a negative regulator of cell proliferation (Isola et al. 1992, Hartmann et al. 1997, van Slooten et al. 1999). Therefore, the observed decrease 

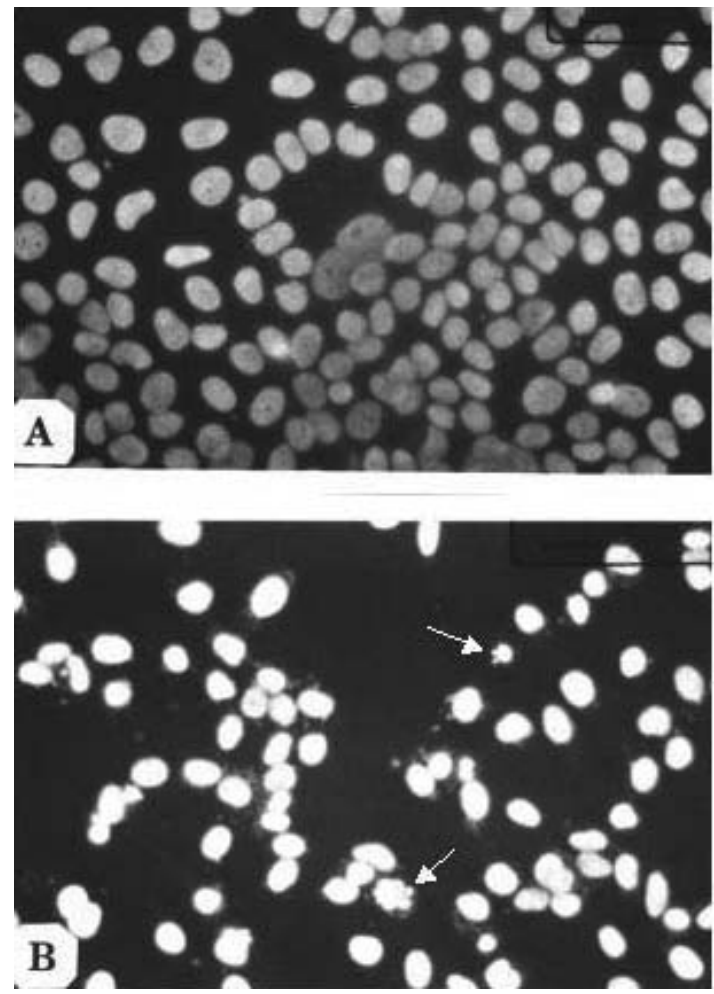

Figure 9 Effect of progesterone on apoptosis in transfected MCF-7 cells. Cells were either transiently transfected with CMV-p53 vector or with the empty CMV vector. The cells were then treated with vehicle alone (A) or with $100 \mathrm{nM}$ progesterone for 4 days (B). The 4,6-diamidino-2-phenylindol (DAPI, $1 \mu \mathrm{g} / \mathrm{ml}$ ) staining method was used to identify cells undergoing apoptosis. The stained nuclei were visualized under a Zeiss Axioplan microscope using a UV filter in the range of 395-450 $\mathrm{nm}$. Condensed or fragmented nuclei were scored as apoptotic cells. Arrows indicate fragmented nuclei.

in p53 levels in MCF-7 breast cancer cells treated with progesterone may be involved in the protection of MCF-7 cells from dying by apoptosis. In order to check whether the sensitivity of MCF-7 cells can be altered by the level of cellular p53 protein, we overexpressed p53 by using a p53 cDNA expression vector. We show in this report that re-establishing p53 protein levels in the cells by exogenous expression renders the cells more sensitive to progesterone and that the observed increase in growth inhibition rate was due to the induction of cell death by apoptosis. In pre-clinical model systems it was demonstrated that many types of tumors with wild-type p53 status responded better to certain oncological therapeutic modalities than tumors with an altered p53 status (Clarke et al. 1993, Lowe et al. 1993, 1994, O'Connor et al. 1993, Fan et al. 1994). However, none of these therapeutic modalities included progesterone. In the absence of the tumor suppressor gene p53 in the mammary epithelial cell model, progesterone facilitates chromosomal instability (aneuploidy) (Goepfert et al. 2000). This supports the hypothesis that progesterone markedly enhances mammary tumorigenesis in the absence of p53 protein. At the present time, little is known regarding the efficacy of progesterone treatment in relation to endogenous p53 levels in the tumor (O'Connor et al. 1998). To our best knowledge, our data is the first to correlate the effect of progesterone on human breast cancer cell proliferation with the status of p53 in the cells. In conclusion, our data show that the effect of progesterone on growth inhibition and apoptosis is enhanced in cultured MCF-7 cells that overexpress p53 protein and suggest that re-establishing p53 function may render breast cancer cells more sensitive to the growth inhibitory effect of progesterone. In other words, p53 levels appear to dictate the mechanism(s) whereby progesterone exerts antiproliferative effects on MCF-7 cells. Down-regulation of p53 favors cellular differentiation, whereas its upregulation forces the cells additionally to undergo apoptosis. Therefore, the rationale of the use of progesterone in hormone replacement therapy for breast cancer should be evaluated in relation to the p53 status of the tumors.

\section{Acknowledgements}

We thank Professor Christopher H J Ford for his critical reading of the manuscript and Maya Bakir and Lilly Verghese for technical assistance.

\section{Funding}

M A was supported by Kuwait University Research Administration grant MB 028.

\section{References}

Alkhalaf M \& Murphy LC 1992 Regulation of c-jun and jun-B by progestins in T47D human breast cancer cells. Molecular Endocrinology 6 1625-1633.

Alkhalaf M, El-Mowafy A \& Karam S 2002 Growth inhibition of MCF-7 human breast cancer cells by progesterone is associated with cell differentiation and phosphorylation of Akt protein. European Journal of Cancer Prevention 11 481-488.

Castoria G, Barone MV, Di Domenico M, Bilancio A, Ametrano D, Migliaccio A \& Auricchio F 1999 Non-transcriptional action of oestradiol and progestin triggers DNA synthesis. EMBO Journal 18 2500-2510.

Clarke A, Purdie C, Harrison D, Morris R, Bird C, Hooper M \& Wyllie A 1993 Thymocyte apoptosis induced a p53-dependent and -independent pathway. Nature 362 849-852.

Clarke CL \& Sutherland RL 1990 Progestin regulation of cellular proliferation. Endocrine Review 11 266-301.

Fan S, El-Deiry W, Bae I, Freeman J, Jondle D, Bahatia K, Fornace A Jr, Magrath I, Kohn K \& O'Connor P 1994 p53 gene mutations are associated with decreased sensitivity of human lymphoma cells to DNA damaging agents. Cancer Research $\mathbf{5 4}$ 5824-5830.

Formby B \& Wiley TS 1998 Progesterone inhibits growth and induces apoptosis in breast cancer cells: inverse effects on Bcl-2 and p53. Annals of Clinical and Laboratory Science 28 360-369. 
Formby B \& Wiley TS 1999 Bcl-2, survivin and variant CD44 v7-v10 are downregulated and $\mathrm{p} 53$ is upregulated in breast cancer cells by progesterone: inhibition of cell growth and induction of apoptosis. Molecular and Cellular Biochemistry 202 53-61.

Goepfert TM, McCarthy M, Kittrell FS, Stephens C, Ullrich RL, Brinkley BR \& Medina D 2000 Progesterone facilitates chromosome instability (aneuploidy) in p53 null normal mammary epithelial cells. FASEB Journal 14 2221-2229.

Hartmann A, Blaszyk H, Kovach JS \& Sommer SS 1997 The molecular epidemiology of $\mathrm{p} 53$ gene mutations in human breast cancer. Trends in Genetics 13 27-33.

Horita K, Inase N, Miyake S, Formby B, Toyoda H \& Yoshizawa Y 2001 Progesterone induces apoptosis in malignant mesothelioma cells. Anticancer Research 21 3871-3874.

Horwitz KB 1993 Mechanisms of hormone resistance in breast cancer. Breast Cancer Research and Treatment 26 119-130.

Isola J, Visakorpi T, Holli K \& Kallioniemi OP 1992 Association of overexpression of tumor suppressor protein p53 with rapid cell proliferation and poor prognosis in node-negative breast cancer patients. Journal of the National Cancer Institute 84 1109-1114.

Kester HA, van der Leede BM, van der Saag PT \& van der Burg B 1997 Novel progesterone target genes identified by an improved differential display technique suggests that progestin-induced growth inhibition of breast cancer cells coincides with enhancement of differentiation. Journal of Biological Chemistry 272 16637-16643.

Lane DP 1994 The regulation of p53 function. International Journal of Cancer 57 623-627.

Lange CA, Richer JK \& Horwitz KB 1999 Hypothesis: progesterone primes breast cancer cells for cross-talk with proliferative or antiproliferative signals. Molecular Endocrinology 13 829-836.

Levine AJ 1997 p53, the cellular gatekeeper for growth and division. Cell 88 323-331.

Lowe S, Ruley H, Jacks T \& Housman D 1993 p53-dependent apoptosis modulates the cytotoxicity of anti-cancer agents. Cell $\mathbf{7 4}$ 957-967.

Lowe S, Bodis S, McClatchey A, Remington L, Ruley H, Fisher D, Housman D \& Jacks T 1994 p53 status and the efficacy of cancer therapy in vivo. Science 266 807-810.

Moore MR, Conover JL \& Franks KM 2000 Progestin effects on long-term growth, death, and $\mathrm{Bcl}-\mathrm{xL}$ in breast cancer cells. Biochemical and Biophysical Research Communications 277 650-654.

Moudgil VK, Dinda S, Khattree N, Jhanwar S, Alban P \& Hurd C 2001 Hormonal regulation of tumor suppressor proteins in breast cancer cells. Journal of Steroid Biochemistry and Molecular Biology 76 105-117.

Musgrove EA, Hui R, Sweeney KJ, Watts CK \& Sutherland RL 1996 Cyclins and breast cancer. Journal of Mammary Gland Biology and Neoplasia 1 153-162.
O'Connor IF, Shembekar MV \& Shousha S. 1998 Breast carcinoma developing in patients on hormone replacement therapy: a histological and immunohistological study. Journal of Clinical Pathology 51 935-938.

O'Connor P, Jackman J, Jondle D, Bahatia K, Magrath I \& Kohn K 1993 Role of the p53 tumor suppressor gene in cell cycle arrest and radiosensitivity of Burkitt's lymphoma cell lines. Cancer Research $\mathbf{5 3}$ 4776-4780.

Olivier M \& Hainaut P 2001 Tp53 mutation patterns in breast cancers: searching for clues of environmental carcinogenesis. Seminars in Cancer Biology 11 353-360.

Ory K, Lebeau J, Levalois C, Bishay K, Fouchet P, Allemand I, Therwath A \& Chevillard S 2001 Apoptosis inhibition mediated by medroxyprogesterone acetate treatment of breast cancer cell lines. Breast Cancer Research and Treatment 68 187-198.

Osborne CK 1998 Steroid hormone receptors in breast cancer management. Breast Cancer Research and Treatment 51 227-238.

Pasqualini JR, Paris J, Sitruk-Ware R, Chetrite G \& Botella J 1998 Progestins and breast cancer. Journal of Steroid Biochemistry and Molecular Biology 65 225-235.

Santen RJ, Manni A, Harvey H \& Redmond C 1990 Endocrine treatment of breast cancer in women. Endocrine Review 11 221-265.

Schafer JM, Lee ES, O'Regan RM, Yao K \& Jordan VC 2000 Rapid development of tamoxifen-stimulated mutant $\mathrm{p} 53$ breast tumors (T47D) in athymic mice. Clinical Cancer Research 11 4373-4380.

van Slooten HJ, van De Vijver MJ, Borresen AL, Eyfjord JE, Valgardsdottir R, Scherneck S, Nesland JM, Devilee P, Cornelisse CJ \& van Dierendonck JH 1999 Mutations in exons 5-8 of the p53 gene, independent of their type and location, are associated with increased apoptosis and mitosis in invasive breast carcinoma. Journal of Pathology 189 504-513.

Sutherland RL, Prall OW, Watts CK \& Musgrove EA 1998 Estrogen and progestin regulation of cell cycle progression. Journal of Mammary Gland Biology and Neoplasia 3 63-72.

Swarbrick A, Lee CS, Sutherland RL \& Musgrove EA 2000 Cooperation of p27(kip) and p18(INK4c) in progestin-mediated cell cycle arrest in T47D breast cancer cells. Molecular and Cellular Biology 20 2581-2591.

Thuneke I, Schulte HM \& Bamberger AM 2000 Biphasic effect of medroxyprogesterone-acetate (MPA) treatment on proliferation and cyclin D1 gene transcription in T47D breast cancer cells. Breast Cancer Research and Treatment 63 243-248.

Received 16 June 2003

Accepted 25 June 2003

Made available online as an

Accepted Preprint 27 June 2003 